\title{
AVALIAÇÃO DAS BOAS PRÁTICAS ATRAVÉS DE CHECK- LIST APLICADO EM RESTAURANTES SELF-SERVICE
}

\author{
COELHO, M.B. ${ }^{1 *}$;CRUZ, L.F. ${ }^{1}$; SOARES, L.A. ${ }^{1 ;}$ SOUZA, R.O. ; \\ OLIVEIRA,L.F.3; GOMES,A.A. ${ }^{2}$; SOARES,J.O. ${ }^{2}$; MAGALHÃES, J. T. ${ }^{3}$ \\ ${ }^{\text {I} A l u n o s ~ d e ~ g r a d u a c ̧ a ̃ o ~ d a ~ U n i v e r s i d a d e ~ F e d e r a l ~ d e ~ S a ̃ o ~ J o a ̃ o ~ d e l-R e i, ~ C a m p u s ~ C C O, ~}$ \\ ${ }^{2}$ Auditoras da Secretaria Municipal de Saúde/Divinópolis/MG, \\ ${ }^{3}$ Professores da Universidade Federal de São João del-Rei, Campus CCO. \\ *e-mail:marinabelico@hotmail.com
}

\section{Resumo}

Segundo a Organização Mundial de Saúde (OMS), o crescimento de casos de doenças transmitidas por alimentos em todo mundo está ligado, entre outros fatores, à falta de higiene no preparo destes. As doenças transmitidas por alimentos constituem um grande problema de saúde pública sendo responsáveis por elevados custos econômicos e sociais. O presente trabalho teve como objetivo avaliar as condições de higiene no preparo de alimentos em sete restaurantes do tipo self-service no centro da cidade de Divinópolis, MG. Foi aplicado um check-list (guia de verificação) baseado na legislação vigente do país. Para tal, ele foi organizado em três módulos (1-edificação e instalação, 2limpeza e organização e 3-características dos alimentos), os quais foram divididos em 13 itens e por sua vez, subdivididos em 48 sub-itens. Estes foram agrupados de acordo com aspectos considerados imprescindíveis (sub -itens críticos para a proteção contra surtos de doenças alimentares e que necessitam de correção imediata quando não atendidos), necessários (sub-itens não essenciais para o controle efetivo das doenças causadas por alimentos, mas que contribuem para a ocorrência destas) e recomendáveis (não críticos para a proteção contra surtos de doenças alimentares, mas que atendem as boas práticas). Desta forma, os resultados mostram que os sete restaurantes avaliados obtiveram uma variação de conformidade dos sub-itens imprescindíveis de 41,4 a $52,7 \%$, os necessários 54,5 a $56,3 \%$ e os recomendáveis 55,5 a $64,9 \%$. Conclui-se assim que a maioria dos restaurantes pesquisados não possui condições de higiene satisfatória, de forma que não atendem as regras básicas para obtenção de alimentos seguros. Portanto, é de extrema importância a 
aplicação periódica deste guia de verificação por proprietários de restaurantes, de forma que o processamento e distribuição das refeições sejam linhas cruciais de defesa na prevenção de toxinfecções.

Palavras-chave: boas práticas, self-service, alimentos.

Agência Fomento: FAPEMIG, CNPq e UFSJ 